\title{
NEW THERAPEUTIC APPROACHES IN TYPE 2 DIABETES
}

\author{
André J. Scheen \\ Division of Diabetes, Nutrition and Metabolic Disorders, \\ Department of Medicine, CHU Sart Tilman, Liège, Belgium.
}

Short title : New drugs in type 2 diabetes

Address for correspondence :

\author{
Pr André J. SCHEEN \\ Department of Medicine \\ CHU Sart Tilman (B35) \\ B-4000 LIEGE 1 \\ BELGIUM \\ Phone : 32-4-3667238 \\ FAX : 32-4-3667068 \\ Email : andre.scheen@chu.ulg.ac.be
}

\section{Summary}

Type 2 diabetes is a progressive chronic disease resulting from a dynamic interaction between defects in insulin secretion and insulin action. New molecules have recently been launched and many others are under clinical investigation. Besides classical sulfonylureas and glinides, new insulin secretagogues are now available, which target the incretin gut hormone glucagon-like peptide-1 (GLP1). Indeed, oral incretin enhancers acting as antagonists of the enzyme DPP-4 (dipeptidylpeptidase-4), 
which inactivates natural GLP-1, and injectable incretin mimetics (exenatide) or analogues (liraglutide), which reproduce the actions of GLP-1 while resisting to DPP-4, represent new opportunities to stimulate insulin secretion, without increasing the risk of hypoglycaemia and weight gain. Among insulin sensitizers, metformin remains unequivocally the first drug of choice for the treatment of type 2 diabetes, whereas promising drugs as thiazolidinediones (glitazones) were recently challenged because of various safety issues. When insulin is required, insulin analogues, both short-acting and basal ones, may offer some advantages regarding better control of postprandial hyperglycaemia, reduced risk of hypoglycaemia and/or lower weight gain in patients with type 2 diabetes. Emphasis should be put on early detection and intensive management of type 2 diabetes, individualized glucose lowering treatments and goals, stepwise pharmacological strategy avoiding therapeutic inertia, and multiple cardiovascular risk-targeted approach.

Key-words : Incretins - Insulin analogues - Oral antidiabetic agents - Exenatide - Type 2 diabetes

\section{Résumé}

Le diabète de type 2 est une maladie chronique progressive résultant de l’interaction dynamique entre un déficit de la sécrétion et un déficit de l'action de l'insuline. Plusieurs nouveaux médicaments ont été commercialisés récemment et beaucoup d’autres sont en développement clinique. A côté des sulfamides hypoglycémiants et des glinides, de nouveaux insulinosécrétagogues sont maintenant disponibles qui ciblent l'hormone incrétine digestive glucagon-like peptide-1 (GLP-1). En effet, des médicaments antagonisant la dipeptidylpeptidase-4 (DPP-4), enzyme qui inactive le GLP-1 naturel, et des incrétinomimétiques (exénatide) ou des analogues du GLP-1 (liraglutide), qui reproduisent les actions du GLP-1 tout en résistant à la DPP-4, représentent de nouvelles opportunités pour stimuler la sécrétion d'insuline, sans accroître le risque d'hypoglycémies et de prise de poids. Parmi les médicaments améliorant l'action de l'insuline, la metformine reste, de façon indiscutable, l'antidiabétique oral de premier choix, tandis que des médicaments prometteurs comme les thiazolidinediones (glitazones) ont été récemment controversés en raison de divers problèmes de sécurité et de tolérance. Lorsque l’insuline devient nécessaire, les analogues de l'insuline, de durée ultra-courte et à action basale, peuvent offrir certains avantages en ce qui concerne le contrôle de l’hyperglycémie post-prandiale, la réduction du risque hypoglycémique et/ou une moindre prise pondérale chez les patients diabétiques de type 2. Il convient d'insister sur l'importance d'une détection 
précoce et d'une prise en charge intensive du diabète de type 2 , d'une individualisation des traitements hypoglycémiants et des objectifs thérapeutiques, d'une stratégie pas à pas proactive, évitant l'inertie thérapeutique, et d’une approche de prévention cardio-vasculaire multi-risques. 


\section{Introduction}

Type 2 diabetes is a heterogeneous condition caused by both genetic and environmental factors. Hyperglycaemia results from a dynamic interaction between defects in insulin secretion and insulin action $(1,2)$. Type 2 diabetes is generally characterized by a progressive deterioration of the metabolic status over years, which essentially results from an unavoidable decline of insulin secretion. Therefore, the management of the disease generally requires a stepwise adjustment of pharmacological therapies in combination with life-style changes, which ultimately may lead to insulin requirement $(3,4,5)$. Such a strategy includes a progressive increase in the daily dosages of each molecule used and/or appropriate combinations of various glucose-lowering agents with complementary and, ideally, synergistic modes of action (5,6).

Because most patients with type 2 diabetes are overweight or obese (7), the treatment of choice is optimization of the meal plan and enhancement of physical activity $(3,8)$. Various oral antihyperglycaemic agents have been developed during the last 60 years (6,9). Mechanisms of action aim at targeting insulin secretion (sulfonylureas, meglitinide analogues) or insulin action (metformin, thiazolidinediones) (10). When oral therapy is not able to control blood glucose, insulin replacement therapy should be started. The place of insulin analogues (so-called "modern insulins") (11) and the type of insulin regimens (12) in the management of type 2 diabetes remain a matter of discussion. Recommendations for the management of type 2 diabetes have been published by an ADA-EASD consensus in 2006, and updated in 2008 (4). However, these guidelines have to be updated because of the recent launch of new compounds, essentially those targeting glucagon-like peptide-1 (GLP-1) and known as “incretins" $(13,14)$. The present review paper aims at describing novel drugs recently launched, with the main objectives to stimulate insulin secretion, promote insulin action or replace insulin deficiency (Table 1).

\section{New insulin secretagogues : “incretins”}

Classical insulin secretagogues include sulfonylureas for more than 50 years and, more recently, glinides (repaglinide, nateglinide) (5,6). However, these compounds, which close $\mathrm{K}^{+}$channels in the Bcell membrane, stimulate insulin secretion independently of glucose levels, and therefore expose diabetic patients to a risk of hypoglycaemia and weight gain. New compounds targeting the incretin hormone system may offer some advantages regarding such adverse events. GLP-1 is normally secreted by the $\mathrm{L}$ cells of the ileon, but its post-meal secretion is decreased in patients with type 2 diabetes. 
Furthermore, GLP-1 is rapidly inactivated by an enzyme called dipeptidylpeptidase-4 (DDP-4) (13). GLP-1 represents a key- target hormone for the management of type 2 diabetes. Indeed, it improves glycaemic control through glucose-dependent stimulation of insulin secretion, suppression of glucagon secretion, slowing of the gastric emptying and reducing appetite (Figure 1). There are two ways to increase GLP-1 action, either by inhibiting DPP-4 and thus enhancing the effects of naturally-secreted GLP-1, or by injecting GLP-1 mimetics or analogues that resist to the action of DPP-4 $(13,14,15)$.

\subsection{Incretin enhancers : DPP-4 antagonists}

Sitagliptin is the first selective antagonist of DPP-4 $(16,17)$. It increases post-meal insulin secretion (« incretin effect) by enhancing the postprandial GLP-1 response (“incretin enhancer”), in a glucose-dependent manner. It improves glycaemic control (glycated haemoglobin or HbA1c) in type 2 diabetic patients treated by diet alone, by metformin, by sulfonylurea, by glitazone or by a metformin-sufonylurea combination therapy. The glucose-lowering effect is similar to that of glipizide, but with the advantage of absence of weight gain and no hypoglycaemic episodes. The tolerance to sitagliptin is excellent. Treatment is simple, with $100 \mathrm{mg}$ once daily, without need of titration or home blood glucose monitoring.

Other DPP-4 antagonists (also called gliptins) are already commercialized (vildagliptin) or are in late phase of clinical development (saxagliptin). The best place of the DPP-4 antagonists in the management of type 2 diabetes is in combination with metformin, so that several fixed-dose combinations are already available or will be commercialized soon. Nevertheless, the DDP-4 antagonists are not considered in the recently updated consensus algorithm of the ADA-EASD (4).

\subsection{GLP-1 mimetics and analogues}

Exenatide is a synthetic derivative of exendin- 4 and an agonist of receptors of GLP-1 (18). It is resistant to the rapid inactivation by DPP-4 and acts as an incretin mimetic. It stimulates insulin secretion by the $\mathrm{B}$ cell in a glucose-dependent manner whereas it inhibits glucagon secretion. Exenatide improves mainly postprandial glucose concentrations and lowers HbA1c levels, without being directly responsible for hypoglycaemia or requiring mandatory home blood glucose monitoring. Furthermore, it slows gastric emptying and promotes sustained body weight reduction, even in absence of frequently reported nausea following treatment initiation. The recommended initial dose is a subcutaneous injection of $5 \mu \mathrm{g}$ before morning and evening meals in 
order to minimize initial gastrointestinal side-effects, to be up titrated to $10 \mu \mathrm{g}$ twice daily. Exenatide may represent a valuable alternative to insulin therapy, especially in overweight or obese patients with type 2 diabetes without too severe fasting hyperglycaemia and not ready to perform home blood glucose monitoring (19). A once weekly formulation is being developed, which seems even more active and better tolerated (20).

Liraglutide is a GLP-1 analogue, which is obtained by derivatising GLP-1 with a fatty acid, providing a compound resistant to DPP-4, with pharmacokinetic properties that are suitable for once-daily dosing (21). A recent 52-week randomised controlled trial demonstrated that liraglutide as monotherapy leads to greater reductions in HbA1c, body weight, hypoglycaemia and blood pressure than does the sulfonylurea compound glimepiride (22). Liraglutide is well tolerated. The adverse events that are most frequently reported are transient nausea and diarrhoea (21). Rare cases of pancreatitis were recently reported during treatment with liraglutide (22), as it was also the case with exenatide, and such adverse event deserves further investigation. The compound is in the late phase of clinical development and should be commercialized in a near future.

\section{New insulin sensitizers}

Insulin resistance plays a key-role in the pathophysiology of type 2 diabetes $(1,2)$. Metfomin improves insulin action, mainly in the liver, thus contributing to a reduction of the hepatic glucose output. Despite its use since more than 50 years, metformin is still considered as the drug of first choice in the management of type 2 diabetes in more recent guidelines (4). In the United Kingdom Diabetes Prevention Study (UKPDS), metformin significantly reduced the risk of complications associated to diabetes, including remarkably the incidence of myocardial infarction, and these favourable effects were recently shown to persist 10 years after the end of the study (23). Insulin resistance of type 2 diabetes is closely associated with abdominal obesity and the so-called adiposopathy $(7,8)$. Therefore, new compounds have been developed to more specifically target insulin resistance, either acting as agonists of the nuclear PPAR-gamma receptors (Peroxisome Proliferative Activated Receptors-gamma) predominantly in the adipose tissue (24) or acting as antagonists of the CB1 endocannabinoid receptors present in the central nervous system but also in the adipose tissue and other various peripheral organs (25).

\subsection{PPAR-gamma agonists : glitazones}

Thiazolidinediones or glitazones (pioglitazone, rosiglitazone) act as PPAR-gamma agonists and 
are considered as insulin sensitizers. Considering this mode of action, they were expected to reduce the burden on the B cells and even protect the B cells and thus to offer a better durability of the glucoselowering effect as compared to other classical oral antidiabetic agents such as metformin or sulfonylureas. This was recently confirmed in ADOPT (“A Diabetes Outcome Progression Trial”) (26). In addition, great hope was put on a plausible cardiovascular protection, which was, at least partially, confirmed in PROactive («PROspective pioglitAzone Clinical Trial In macroVascular Events ») comparing pioglitazone versus placebo in type 2 diabetic patients with a high cardiovascular risk (27). However, a big controversy arose after the publication of a meta-analysis suggesting a higher cardiovascular risk with rosiglitazone as compared to other comparators (28). The use of glitazones is contraindicated in patients with or at risk of congestive heart failure and should be avoided in combination with insulin. Furthermore, the cardiovascular risk/benefit ratio should be assessed in every diabetic patient before prescribing a thiazolidinedione. Nevertheless, pioglitazone (but not rosiglitazone) is still considered as an option for second-line therapy in the management of type 2 diabetes (4).

\subsection{CB1 receptor antagonists : rimonabant}

Several animal and human observations suggest that the endocannabinoid (EC) system is overactivated in presence of abdominal obesity and/or diabetes, and contributes to disturbances of energy balance and metabolism control (25). It regulates not only the intake of nutrients through central mechanisms located within the hypothalamus and limbic area, but it also intervenes in transport, metabolism and deposit of the nutrients in various organs playing a key-role in the pathophysiology of type 2 diabetes (Figure 1). Activation of both central and peripheral CB1 receptors promotes weight gain and associated metabolic changes. Conversely, rimonabant, the first selective $\mathrm{CB}_{1}$ receptor antagonist, has been shown to reduce body weight, waist circumference, triglycerides, blood pressure, insulin resistance and C-reactive protein levels, and to increase HDL cholesterol and adiponectin concentrations in both non-diabetic and diabetic overweight/obese patients. In addition, a 0.5-0.7\% reduction in HbA1c levels was observed in patients with type 2 diabetes treated with metformin- or sulfonylurea, with diet alone or with insulin. Almost half of the metabolic changes occurred beyond weight loss, in agreement with direct peripheral effects (29). Rimonabant was generally well-tolerated, but with a higher incidence of depressed mood disorders and anxiety, contraindicating its use in patients with antecedents of severe depression or treated with antidepressants. However, late October 2008, the European Medicines Agency (EMEA) 
requested to temporary suspend the marketing authorisation of rimonabant.for the approved indication of obese and overweight patients with metabolic risk such as diabetes and dyslipidaemia because severe depression may occur in individuals without any risk factor except obesity itself.

\section{New insulin analogues}

Classical insulin formulations have the inconvenience of acting in a too slow and prolonged manner as far as regular ("rapid") insulin is concerned and in a too short and non-reproducible manner as far as intermediate insulin (NPH) is concerned . These characteristics led to several adverse events, such as poor prandial glucose control and higher risk of hypoglycaemia, especially at night. Therefore, the pharmaceutical companies successfully developed analogues of insulin, by modifying some amino acids in the sequence of insulin molecule. This led to the launch of ultra-short acting insulin analogues (aspart, glulisine, lispro), on one hand, and of basal insulin analogues (glargine, detemir), on the other (11). As compared to classical insulin formulations, these new insulin analogues do not necessarily improve overall glucose control (as assessed by Hb1A1c levels), but are associated with better prandial glucose control, lower risk of (nocturnal) hypoglycaemia, better reproducibility of fasting glycaemia and/or slightly lower weight gain (11). As classical insulin formulations, these new insulin analogues can be injected once a day as add-on basal insulin therapy to oral agents, twice (or threefold) daily with the use of premixed insulin formulations or four times daily when a basal-prandial insulin regimen is selected. Each insulin regimen has its own advantages and disadvantages and the choice should be based on individual patient characteristics (12).

\section{Conclusions}

Type 2 diabetes mellitus is a complex disease whose treatment remains a real challenge. Indeed, none of the classical pharmacological treatments used for the last decades were able to avoid the progression of the disease and the metabolic deterioration over years. Furthermore, aggressive glucose lowering therapy exposes diabetic patients to adverse effects such as hypoglycaemia and weight gain, which may be harmful and counterproductive as treatment compliance is concerned. The development of new compounds aims at improving glucose control in a more efficacious and safer manner. Incretins appear to offer great opportunities in this respect, but longer clinical risk/benefit assessment is still required (30). Other agents were recently launched and new compounds are still in development, so that the pharmacological opportunities, as monotherapy or combined therapies, are becoming more and more numerous and complex. Such new advances raise further concern about the urgent need of clear- 
cut recommendations for first-line health care providers, the challenge of drug compliance and the problem of increasing cost.

\section{References}

1. Scheen AJ. Pathophysiology of type 2 diabetes. Acta Clin Belg 2003; 58: 335-41.

2. Stumvoll M, Goldstein BJ, van Haeften TW. Type 2 diabetes: principles of pathogenesis and therapy. Lancet 2005; 365: 1333-46.

3. American Diabetes Association. Standards of medical care in diabetes-2008. Diabetes Care 2008; 31 (Suppl 1): S12-54.

4. Nathan DM, Buse JB, Davidson MB, et al. - Medical management of hyperglycemia in type 2 diabetes: a consensus algorithm for the initiation and adjustment of therapy. A consensus statement of the American Diabetes Association and the European Association for the Study of Diabetes. Diabetes Care 2008, 31, Oct 22. [Epub ahead of print].

5. Scheen AJ, Lefèbvre PJ. Oral antidiabetic agents : a guide to selection. Drugs 1998; 55: 225-36.

6. Krentz AJ, Bailey CJ. Oral antidiabetic agents. Current role in type 2 diabetes mellitus. Drugs 2005; 65: 385-411.

7. Scheen AJ. Current management of coexisting obesity and type 2 diabetes. Drugs 2003; 63: 1165-84.

8. Scheen AJ. Treatment of type 2 diabetes. Acta Clin Belg 2003; 58: 318-24.

9. Scheen AJ. Drug treatment of non-insulin-dependent diabetes mellitus in the 1990s : achievements and future developments. Drugs 1997; 54: 355-68.

10. Scheen AJ, Radermecker RP, Philips JC, et al . Le traitement du diabète de type 2 : entre insulinosensibilisateurs et insulinosécrétagogues. Rev Med Liège 2007; 62 (numéro spécial Synthèse) : 40-6.

11. Oiknine R, Bernbaum M, Mooradian AD. A critical appraisal of the role of insulin analogues in the management of diabetes mellitus. Drugs 2005; 65: 325-40.

12. Holman RR, Thorne KI, Farmer AJ, et al. Addition of biphasic, prandial, or basal insulin to oral therapy in type 2 diabetes. $N$ Engl J Med 2007; 357: 1716-30.

13. Drucker DJ, Nauck MA. The incretin system: glucagon-like peptide-1 receptor agonists and dipeptidyl peptidase-4 inhibitors in type 2 diabetes. Lancet 2006; 368: 1696-705.

14. Ruige JB. Incretin mimetics and enhancers for the treatment of type 2 diabetes mellitus. Acta Clin Belg 2008 ; 63 : 81-5. 
15. Scheen AJ, Radermecker RP, Philips JC, Paquot N. Les incrétinomimétiques et incrétinopotentiateurs dans le traitement du diabète de type 2. Rev Med Suisse 2007; 3: 1884-8.

16. Idris S, Donnelly R. Dipeptidyl peptidase-IV inhibitors : a major new class of oral antidiabetic drug. Diab Obes Metab 2007; 9: 153-65.

17. Lyseng-Williamson KA. Sitagliptin. Drugs 2007; 67: 587-97.

18. Cvetkovic RS, Plosker GL. Exenatide: a review of its use in patients with type 2 diabetes mellitus (as an adjunct to metformin and/or a sulfonylurea). Drugs 2007; 67: 935-54.

19. Van Gaal LF, Gutkin SW, Nauck MA. Exploiting the antidiabetic properties of incretins to treat type 2 diabetes mellitus: glucagon-like peptide-1 receptor agonists or insulin for patients with inadequate glycemic control ? Eur J Endocrinol 2008; 158: 773-84.

20. Drucker DJ, Buse JB, Taylor K, et al, for the DURATION-1 Study Group. Exenatide once weekly versus twice daily for the treatment of type 2 diabetes. Lancet 2008; 372: 1240-50.

21. VilsbØll T. Liraglutide: a once-daily GLP-1 analogue for the treatment of type 2 diabetes mellitus. Expert Opin Investig Drugs 2007; 16: 231-7.

22. Garber A, Henry R, Ratner R, et al. Liraglutide versus glimepiride monotherapy for type 2 diabetes (LEAD-3 Mono) : a randomised, 52-week, phase III, double-blind, parallel-treatment trial. Lancet 2008 Sept 24. [Epub ahead of print].

23. Holman RR, Paul SK, Bethel MA, et al. 10-year follow-up of intensive glucose control in type 2 diabetes. $N$ Engl J Med 2008; 359: 1577-89.

24. Yki-Järvinen H. Thiazolidinediones. N Engl J Med 2004; 351: 1106-18.

25. Scheen AJ. The endocannabinoid system : a promising target for the management of type 2 diabetes. Curr Protein Pept Sci 2009; 10: 56-74.

26. Kahn SE, Haffner SM, Heise MA, et al for the ADOPT Study Group. Glycemic durability of rosiglitazone, metformin, or glyburide monotherapy. New Engl J Med 2006; 355: 2427-43.

27. Dormandy J, Charbonnel B, Eckland DJA, et al. Secondary prevention of macrovascular events in patients with type 2 diabetes in the PROactive Study (PROspective pioglitAzone Clinical Trial In macroVascular Events) : a randomised controlled trial. Lancet 2005; 366: 1279-89.

28. Nissen SE, Wolski K. Effect of rosiglitazone on the risk of myocardial infarction and death from cardiovascular causes. N Engl J Med 2007; 356: 2457-2471. 
29. Scheen AJ, Finer N, Hollander P, et al for the RIO-Diabetes Study Group. Efficacy and tolerability of rimonabant in overweight or obese patients with type 2 diabetes: a randomised controlled study. Lancet 2006; 368: 1660-72.

30. Scheen AJ. Exenatide once weekly in type 2 diabetes (comment). Lancet 2008; 372: 11971198.

\section{Legend to the Figure}

Figure 1: $\quad$ Sites of action of classical and new drugs used for the management of type 2 diabetes

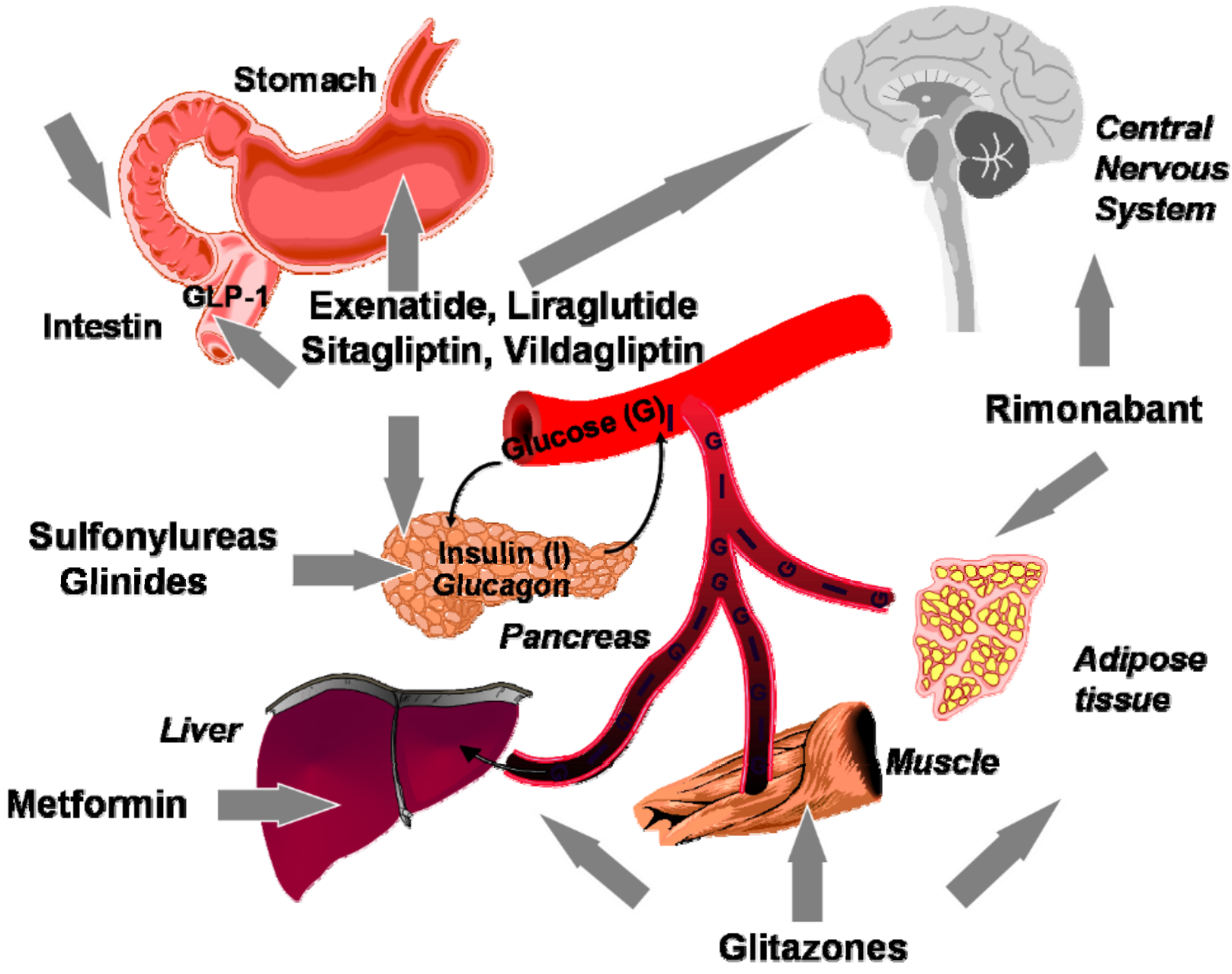


Table 1 : Classical, novel and future agents targeting hyperglycaemia in type 2 diabetes

1) Insulin secretagogues

a. Agents acting on $\mathrm{K}^{+}$channels

i. Sulfonylureas : glibenclamide, gliclazide, glimepiride, glipizide, gliquidone, ...

ii. Glinides : nateglinide, repaglinide

b. Agents acting on GLP-1

i. DPP-4 inhibitors : sitagliptin, vildagliptin, saxagliptin, ...

ii. GLP-1 mimetics : exenatide

iii. GLP-1 analogues : liraglutide, ...

2) Insulin sensitizers
a. Biguanides : metformin
b. Thiazolidinediones : pioglitazone, rosiglitazone
c. CB1 antagonists : rimonabant

3) Insulin analogues
a. Ultra-short acting : aspart, glulisine, lispro
b. Basal : glargine, detemir

4) Agents acting independently of insulin (*)
a. Alpha-glucosidase inhibitors : acarbose
b. Amylin analogues : pramlintide
c. SGLT-2 inhibitors : dapagliflozin, ...

$\left(^{*}\right)$ not further described in the present paper 
